\title{
RELAÇÃO METIONINA E COLINA DIETÉTICA SOBRE O DESEMPENHO DE CODORNAS JAPONESAS (Coturnix coturnix japonica) EM POSTURA
}

\author{
Solange de Faria CASTRo ${ }^{1}$, Bruno Duarte Alves Fortes ${ }^{2}$, JÚlio CÉsar CARRera de \\ CARVALHO ${ }^{1}$, ANTÔNIO GILBERTO BERTECHINI ${ }^{3}$, LIVYA STEFANE BORGES DE QUEIROZ ${ }^{1}$, ANTÔNIO \\ AMANDIO PINTO GARCIA JR ${ }^{1}$ \\ ${ }^{1}$ Pós-graduandos da Universidade Federal de Lavras, Lavras,MG. \\ ${ }^{2}$ Pós-graduando da Escola de Veterinária e Zootecnia da Universidade Federal de Goiás, Goiânia, GO - \\ fortesbruno@zootecnista.com.br \\ ${ }^{3}$ Professor Doutor da Universidade Federal de Lavras, Lavras, MG.
}

\begin{abstract}
Avaliou-se a relação entre níveis de metionina e colina sobre o desempenho de codornas japonesas (Coturnix coturnix japonica) na fase de produção, sendo utilizadas 432 aves com 65 dias de idade e peso médio de $155 \mathrm{~g}$, num delineamento experimental inteiramente casualizado, em esquema fatorial $4 \times 2$ (colina $\mathrm{x}$ metionina) com seis repetições e nove aves por unidade experimental. Os níveis de colina e metionina foram de 0; 200; 400 e 600 ppm e 0,65 e $0,75 \%$, respectivamente. Analisaram-se as variáveis: produção de ovos (\%/ave/dia), pesos dos ovos (g), massa dos ovos (gramas de ovo/ave/dia), conversão alimentar e consumo alimentar (g/d). Observou-se
\end{abstract}

interação significativa para produção de ovos $(\mathrm{P} \leq 0,01)$ e massa de ovos $(\mathrm{P} \leq 0,05)$ com efeito linear para o nível de $0,65 \%$ de metionina e inclusão crescente de níveis de colina. Ocorreu efeito quadrático dos níveis de colina para consumo de ração, com nível de $0,65 \%$ de metionina. A utilização de colina em rações de codornas em produção somente tem efeitos sobre o desempenho das aves quando o nível de metionina utilizado for de $0,65 \%$. A suplementação com colina promove um aumento no peso médio dos ovos independente do nível de suplementação de metionina dietética.

PALAVRAS-CHAVE: aminoácido sulfurado; codornas de postura; desempenho; exigência nutricional; nutrição.

\section{DIETARY METHIONINE AND CHOLINE RELATION ON THE PERFORMANCE OF JAPANESE QUAILS (Coturnix coturnix japonica)}

\section{ABSTRACT}

We evaluated the relationship between levels of methionine and choline on the performance of Japanese quails (Coturnix coturnix japonica) at the production stage, using 432 birds at 65 days of age and weighing $155 \mathrm{~g}$, in a completely randomized design in $4 \times 2$ (methionine $\mathrm{x}$ choline) factorial arrangement with six replicates and nine birds per unit. The levels of choline and methionine were $0,200,400$ and $600 \mathrm{ppm}$ and 0.65 and $0.75 \%$, respectively. We analyzed the following variables: egg production ( $\%$ / hen / day), egg weight (g), egg mass (g egg / hen/ day), feed conversion (g/g) and food intake $(\mathrm{g} / \mathrm{d})$. We observed a significant interaction for egg production $(\mathrm{P} \leq 0.01)$ and egg mass $(\mathrm{P} \leq 0.05)$ with linear effect for $0.65 \%$ methionine and inclusion of increasing levels of choline. There was a quadratic effect of choline levels on feed intake, with $0.65 \%$ methionine. The use of choline in diets of quail in production only effects bird performance when $0.65 \%$ methionine level is used. Supplementation with choline causes an increase in average egg weight regardless of the level of dietary methionine supplementation.

KEYWORDS: laying quails; nutrition; nutritional requirements; performance; sulphur amino acids.

Ci. Anim. Bras., Goiânia, v.12, n.4, p. 635 - 641, out./dez. 2011 


\section{INTRODUÇÃO}

O setor avícola é o mais desenvolvido tecnologicamente do agronegócio brasileiro. A coturnicultura vem se desenvolvendo muito na última década, graças aos esforços no desenvolvimento de novas tecnologias de produção, passando de uma atividade alternativa para industrial.

A atividade encontra-se numa fase favorável de sua exploração industrial, principalmente por apresentar características atrativas, como rápido crescimento, precocidade na maturidade sexual, elevada produção de ovos, pequeno consumo de ração e grande resistência a enfermidades, aliadas ao incremento constante no consumo de ovos.

Igualmente ao setor de produção de ovos de poedeiras comerciais, o fator alimentação representa o maior impacto no custo de produção, havendo necessidade de adequar os níveis de nutrientes essenciais que definem o grau de produção da ave e que possam contribuir para melhorar a produtividade do setor. As recomendações nutricionais indicadas pelo NRC (1994) para clima temperado podem não estar adequadas, sendo necessários estudos que possam melhorar a eficiência das rações utilizadas no Brasil.

As rações de codornas são formuladas normalmente utilizando-se a base das recomendações para níveis de proteína bruta, com informações fixas de aminoácidos, sem levar em consideração as modificações que podem ser exigidas quando se formulam rações para aminoácidos, resultando numa excreção excessiva de ácido úrico. O consumo exagerado de aminoácidos leva a um maior gasto de energia e ainda pode provocar uma redução no consumo de ração devido ao excesso desse nutriente circulante no sangue.

Algumas pesquisas têm sido realizadas para determinar as exigências nutricionais de codornas, sobretudo daquelas destinadas à produção de ovos (FREITAS et al., 2005).

Pela facilidade de compra e pelos preços acessíveis, existe uma crescente utilização de aminoácidos sintéticos nas rações, permitindo formulações de mínimo custo com teores de proteína bruta inferiores aos recomendados nas tabelas de exigências nutricionais, porém, atendendo às exigências dos aminoácidos essenciais.

O uso de aminoácidos sintéticos contribui para reduzir os teores de proteína bruta nas rações em relação aos recomendados em tabelas de exigências nutricionais (ROSTAGNO et al., 2011). A suplementação de metionina nas rações de codornas permite essa redução; por outro lado, existe a necessidade da sua adequação com a colina para que haja otimização do seu uso como aminoácido somente, já que a função de metilação é secundária e pode ser contemplada com o uso da colina, ingrediente de menor custo nas rações.

A metionina é considerada o primeiro aminoácido limitante para o desenvolvimento e produção das aves, por ser doadora de radicais metil necessários à biossíntese de colina, creatina, creatinina, poliaminas, epinefrina e melatonina, que são componentes corporais fundamentais ao crescimento normal dos animais.

A colina, considerada um fator lipotrófico, encontrada tanto em células animais como vegetais, pode apresentar-se nas formas livre ou complexada como acetilcolina, lecitina e esfingomielina (VIEIRA et al., 2001). Além de ser precursora da acetilcolina, um neurotransmissor, e da fosfatidilcolina, um elemento estrutural da membrana celular, representa a maior fração lipídica das lipoproteínas transportadoras.

As exigências de colina podem ser influenciadas pelo teor de lipídeos da dieta e aminoácidos sulfurados, uma vez que pode ocorrer sua síntese no fígado a partir da doação de grupos metílicos da metionina (BARROETA et al., 2002).

Em função da interação entre a colina e a metionina, é difícil estabelecer as exigências de colina, devido a diversas variações entre os estudos encontrados na literatura. Além disso, a falta de informações sobre o nível de aminoácidos para codornas japonesas em produção leva à necessidade de mais pesquisas no assunto. Portanto, objetivou-se avaliar a relação entre os níveis de metionina e colina da dieta sobre o desempenho de codornas japonesas durante a fase de produção.

\section{MATERIAL E MÉTODOS}

O experimento foi conduzido no Setor de Avicultura do Departamento de Zootecnia da 
Universidade Federal de Lavras (UFLA/MG). Foram utilizadas 432 codornas japonesas (Coturnix coturnix japonica), com 65 dias de idade e peso inicial médio de $155 \mathrm{~g}$. As aves foram alojadas em gaiolas metálicas de arame galvanizado de $0,60 \mathrm{~m}$ de largura $\mathrm{x} 0,30 \mathrm{~m}$ de comprimento x $0,25 \mathrm{~m}$ de altura, onde receberam as rações experimentais em comedouros tipo calha e bebedouros tipo niple situados de lados opostos na gaiola.

Utilizou-se um delineamento experimental inteiramente casualizado, com oito tratamentos em esquema fatorial $4 \times 2$ (quatro níveis de colina $\mathrm{x}$ dois níveis de metionina), com seis repetições e nove aves por unidade experimental, totalizando 48 parcelas e 432 aves. Foram testados dois níveis de metionina e quatro níveis de colina, sendo adicionados a uma ração basal (Tabela 1), seguindo as recomendações do NRC (1994). Os níveis de metionina e colina testados foram: $0,65 \%$ e $0,75 \%$ e $0 ; 200 ; 400$ e $600 \mathrm{ppm}$, respectivamente.

$\mathrm{Na}$ formulação das dietas experimentais, a ração basal (Tabela 1) foi suplementada com os níveis de DL-metionina (99\%) e de colina, em substituição ao milho. A inclusão da metionina correspondeu aos níveis de $0,894 \%$ (ração basal sem suplementação), $1,544 \%$ e $1,644 \%$ de aminoácidos sulfurados totais (AAST), sendo todas as rações teste isocalóricas, e para os demais aminoácidos as relações foram mantidas por intermédio da suplementação de aminoácidos sintético.

A água foi fornecida à vontade e a ração duas vezes ao dia. Foi adotado um programa de iluminação de 17 horas diárias durante todo o período experimental, sendo único para todos os grupos experimentais.

O desempenho das aves foi avaliado utilizando-se a produção de ovos (\%), consumo de ração (gramas), conversão alimentar (gramas de ração/gramas de ovo), peso de ovos (gramas) e massa dos ovos (gramas de ovo/codorna/dia).

As análises estatísticas dos dados obtidos foram realizadas por meio do software Sistema de Análises de Variância para dados balanceados (SISVAR), descrito por FERREIRA (2000), utilizando-se a análise de regressão para avaliação dos níveis de colina e teste de média com $5 \%$ de probabilidade para comparação dos níveis de metionina.
Tabela 1 - Composição percentual e calculada dos valores nutricionais da dieta basal utilizada para codornas japonesas na fase de postura

\begin{tabular}{|c|c|}
\hline Ingredientes & Ração basal \\
\hline Milho & 45,13 \\
\hline Farelo de soja, $45 \%$ & 33,87 \\
\hline Farelo de trigo & 6,00 \\
\hline Óleo de soja & 5,70 \\
\hline Calcário & 6,75 \\
\hline Fosfato bicálcico 18/24 & 1,26 \\
\hline Sal comum & 0,34 \\
\hline Inerte $^{1}$ & 0,167 \\
\hline DL-metionina & 0,350 \\
\hline L-lisina HCL (78\%) & 0,167 \\
\hline L-treonina (98\%) & 0,056 \\
\hline Cloreto de colina (60\%) & 0,040 \\
\hline Suplemento mineral $^{2}$ & 0,050 \\
\hline Suplemento vitamínico ${ }^{3}$ & 0,100 \\
\hline $\mathrm{BHT}^{4}$ & 0,010 \\
\hline Virginiamicina & 0,010 \\
\hline Total & 100,00 \\
\hline
\end{tabular}

\begin{tabular}{lc}
\hline \multicolumn{2}{c}{ Composição Calculada } \\
\hline Energia Metabolizável (kcal/kg) & 2.900 \\
Proteína bruta (\%) & 20,00 \\
Lisina total (\%) & 1,215 \\
Lisina digestível (\%) & 1,117 \\
Metionina + cistina total (\%) & 0,974 \\
Metionina + cistina digestível & 0,894 \\
Treonina total (\%) & 0,835 \\
Treonina digestível (\%) & 0,730 \\
Metionina total (\%) & 0,313 \\
Metionina digestível (\%) & 0,285 \\
Cálcio (\%) & 0,800 \\
Fósforo disponível (\%) & 0,350 \\
Sódio (\%) & 0,150 \\
\hline
\end{tabular}

Inerte - Caulim.

${ }^{2}$ Premix mineral (composição/kg do produto): Manganês - 160 $\mathrm{g}$; ferro $-100 \mathrm{~g}$; zinco $-100 \mathrm{~g}$; cobre $-20 \mathrm{~g}$; cobalto $-2 \mathrm{~g}$; iodo $-2 \mathrm{~g}$; veículo q.s.p. $-1.000 \mathrm{~g}$.

${ }^{3}$ Premix vitamínico (composição/kg do produto): Vit. A 12.000.000 UI; Vit. D3 - 3.600.000 UI; Vit. E - 3.500 UI; Vit. B1 - $2.500 \mathrm{mg}$; Vit. B2 - $8.000 \mathrm{mg}$; Vit. B6 - $5.000 \mathrm{mg}$; ácido pantotênico - $12.000 \mathrm{mg}$; biotina $-200 \mathrm{mg}$; Vit. K $-3.000 \mathrm{mg}$; ácido fólico - $1.500 \mathrm{mg}$; ácido nicotínico $-40.000 \mathrm{mg}$; Vit. B12 $-20 \mathrm{mg}$; $\mathrm{Se}-150 \mathrm{mg}$; veículo q.s.p. $-1.000 \mathrm{~g}$.

${ }^{4}$ Butil-hidróxi-tolueno (antioxidante). 


\section{RESULTADOS E DISCUSSÃO}

Houve interação $(\mathrm{P} \leq 0,01)$ entre os níveis de inclusão de metionina e de colina nas dietas. $\mathrm{O}$ menor nível de metionina $(0,65 \%)$ provocou aumento linear $(\mathrm{P} \leq 0,05)$ na produção de ovos com elevação dos níveis de suplementação de colina (Tabela 2). Para o maior nível de metionina $(0,75 \%)$, não houve efeito significativo $(\mathrm{P}>0,05)$ dos níveis de colina sobre a produção de ovos.

Esses resultados indicam que o uso de altos níveis de metionina na dieta da codorna em postura dispensa a suplementação dietética com colina, sendo que a biossíntese orgânica suporta as necessidades das aves para máximo desempenho.

Tabela 2 - Desempenho das codornas em produção de acordo com os níveis de metionina da ração

\begin{tabular}{|c|c|c|c|c|c|c|c|}
\hline \multirow{2}{*}{ Variáveis analisadas } & \multirow{2}{*}{ Nível metionina (\%) } & \multicolumn{4}{|c|}{ Nível de colina (ppm) } & \multirow{2}{*}{ Média } & \multirow{2}{*}{$\mathrm{CV}(\%)$} \\
\hline & & 0 & 200 & 400 & 600 & & \\
\hline \multirow{3}{*}{$\begin{array}{l}\text { Produção de ovos } \\
(\%)^{1}\end{array}$} & 0,65 & $86,31^{\mathrm{b}}$ & $90,36^{\mathrm{b}}$ & $93,45^{\mathrm{a}}$ & $96,45^{\mathrm{a}}$ & 91,64 & \multirow{3}{*}{3,84} \\
\hline & 0,75 & $95,67^{\mathrm{a}}$ & $95,63^{\mathrm{a}}$ & $95,73^{\mathrm{a}}$ & $95,37^{\mathrm{a}}$ & 95,60 & \\
\hline & Média & 90,99 & 92,99 & 94,59 & 95,91 & & \\
\hline \multirow{3}{*}{$\begin{array}{l}\text { Consumo de ração } \\
\text { (g) }\end{array}$} & 0,65 & 24,14 & 25,22 & 27,03 & 25,74 & 25,53 & \multirow{3}{*}{4,27} \\
\hline & 0,75 & 25,42 & 26,57 & 25,77 & 26,27 & 26,00 & \\
\hline & Média $^{2}$ & 24,78 & 25,90 & 26,40 & 26,00 & & \\
\hline \multirow{3}{*}{$\begin{array}{l}\text { Peso de ovos } \\
\text { (g) }\end{array}$} & 0,65 & 9,23 & 9,60 & 9,80 & 9,94 & 9,64 & \multirow{3}{*}{2,84} \\
\hline & 0,75 & 9,88 & 10,12 & 10,12 & 10,37 & 10,12 & \\
\hline & Média $^{3}$ & 9,55 & 9,86 & 9,96 & 10,15 & & \\
\hline \multirow{3}{*}{$\begin{array}{l}\text { Conversão alimentar } \\
\text { (g de ração /g de ovo) }\end{array}$} & 0,65 & 2,69 & 2,71 & 2,83 & 2,66 & 2,66 & \multirow{3}{*}{5,16} \\
\hline & 0,75 & 2,66 & 2,71 & 2,64 & 2,62 & 2,73 & \\
\hline & Média $^{4}$ & 2,67 & 2,71 & 2,74 & 2,64 & & \\
\hline \multirow{3}{*}{ 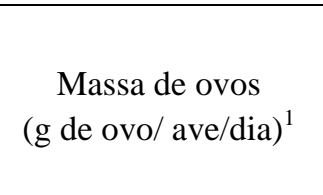 } & 0,65 & $7,97^{\mathrm{c}}$ & $8,70^{\mathrm{b}}$ & $9,18^{\mathrm{ab}}$ & $9,58^{\mathrm{a}}$ & 8,86 & \multirow{3}{*}{3,52} \\
\hline & 0,75 & $9,47^{\mathrm{b}}$ & $9,70^{\mathrm{ab}}$ & $9,68^{\mathrm{ab}}$ & $9,89^{\mathrm{a}}$ & 9,69 & \\
\hline & Média & 8,72 & 9,20 & 9,43 & 9,74 & & \\
\hline
\end{tabular}

${ }^{\mathrm{T}}$ Médias seguidas por letras distintas, minúsculas na linha e maiúsculas na coluna, diferem entre si pelo teste de Tukey $(\mathrm{P} \leq 0,05)$.

${ }^{2}$ Consumo de ração: $Y=23,946278+0,012179 x-0,000015 x^{2} \quad R^{2}=83,11$;

${ }^{3}$ Peso de ovos: $\mathrm{Y}=9,597583+0,000948 \mathrm{x} \quad \mathrm{R}^{2}=95,76$;

${ }^{4}$ Conversão alimentar: $\mathrm{Y}=2,668514+0,000460 \mathrm{x}-0,000001 \mathrm{x}^{2} \quad \mathrm{R}^{2}=88,83$.

Com relação ao consumo de ração, não houve interação entre os fatores $(\mathrm{P}>0,05)$ níveis de metionina e colina dietéticos e nem entre os níveis de metionina utilizados. Mas ocorreu influência dos níveis de colina utilizados nas dietas que, ao serem avaliados por análise de regressão, determinou-se que o maior consumo de ração ocorre com a inclusão estimada de 405,97 ppm de colina (Figura 1). Esses dados, no que se refere a níveis de metionina, concordam com resultados encontrados por MURAKAMI et al. (1994), STRINGHINI et al. (1998) e CORREA et al. (2006), que não observaram efeito significativo de níveis de metionina (aminoácidos sulfurados) sobre o consumo alimentar de codornas japonesas. Por outro lado, trabalhando com codornas japonesas em produção, PINTO et al. (2003a), constataram aumento linear no consumo de ração ao elevar os níveis de AAST da ração. 


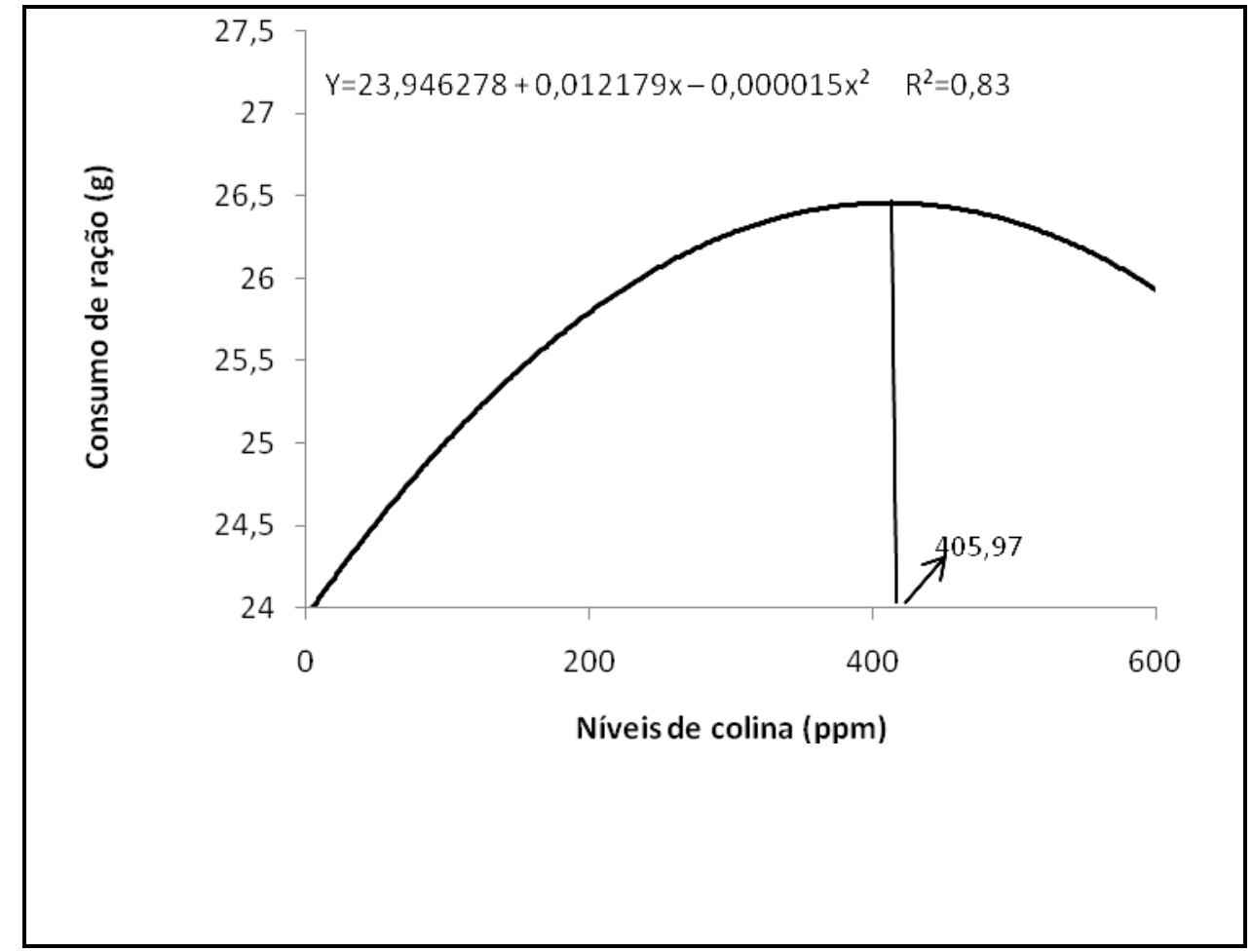

Figura 1- Efeito dos níveis de colina suplementar sobre o consumo médio de ração em codornas japonesas.

Foi verificado com os níveis crescentes de colina, independente do nível de inclusão da metionina, aumento linear no peso médio dos ovos $(\mathrm{P} \leq 0,05)$. Não houve diferença $(\mathrm{P}>0,05)$ entre os níveis de metionina avaliados, corroborando os dados encontrados por MURAKAMI et al. (1994), que analisaram cinco níveis de inclusão de metionina em ração para codornas japonesas e, também, não verificaram diferenças para o peso médio dos ovos.

Da mesma forma, os resultados encontrados por STRINGHINI et al. (1998), utilizando os níveis de $0,45 \%$ e $0,50 \%$ de inclusão de metionina na ração de codornas, também não mostraram influência no peso médio dos ovos. Assim como nos trabalhos de DABBERT et al. (1996), não foram observadas diferenças no peso médio dos ovos entre dietas de baixo, médio e alto nível de metionina. Resultados divergentes foram encontrados por PINTO et al. (2003b) que, ao utilizarem diferentes níveis de AAST digestível, obtiveram efeito quadrático sobre o peso dos ovos. Portanto, apenas a inclusão de metionina não proporciona aumento significativo no peso médio dos ovos, mas pode estar relacionado a um aumento, por meio da sua inter-relação com outros aminoácidos sulfurados.

Houve efeito quadrático para conversão alimentar em função dos níveis de colina e independente dos níveis de metionina (Figura 2). Por outro lado, PINTO et al. (2003b) não verificaram efeito significativo dos níveis de metionina mais cistina sobre a conversão alimentar. Melhoria linear foi obtida por BELO et al. (2000) na conversão alimentar com o aumento do nível de metionina na dieta. As diferenças obtidas entre os resultados dos trabalhos citados com os obtidos neste trabalho podem ser explicadas pelos diferentes níveis utilizados, uma vez que, no presente trabalho, foram utilizados apenas dois níveis e próximos da recomendação de metionina em rações de codornas em postura. 


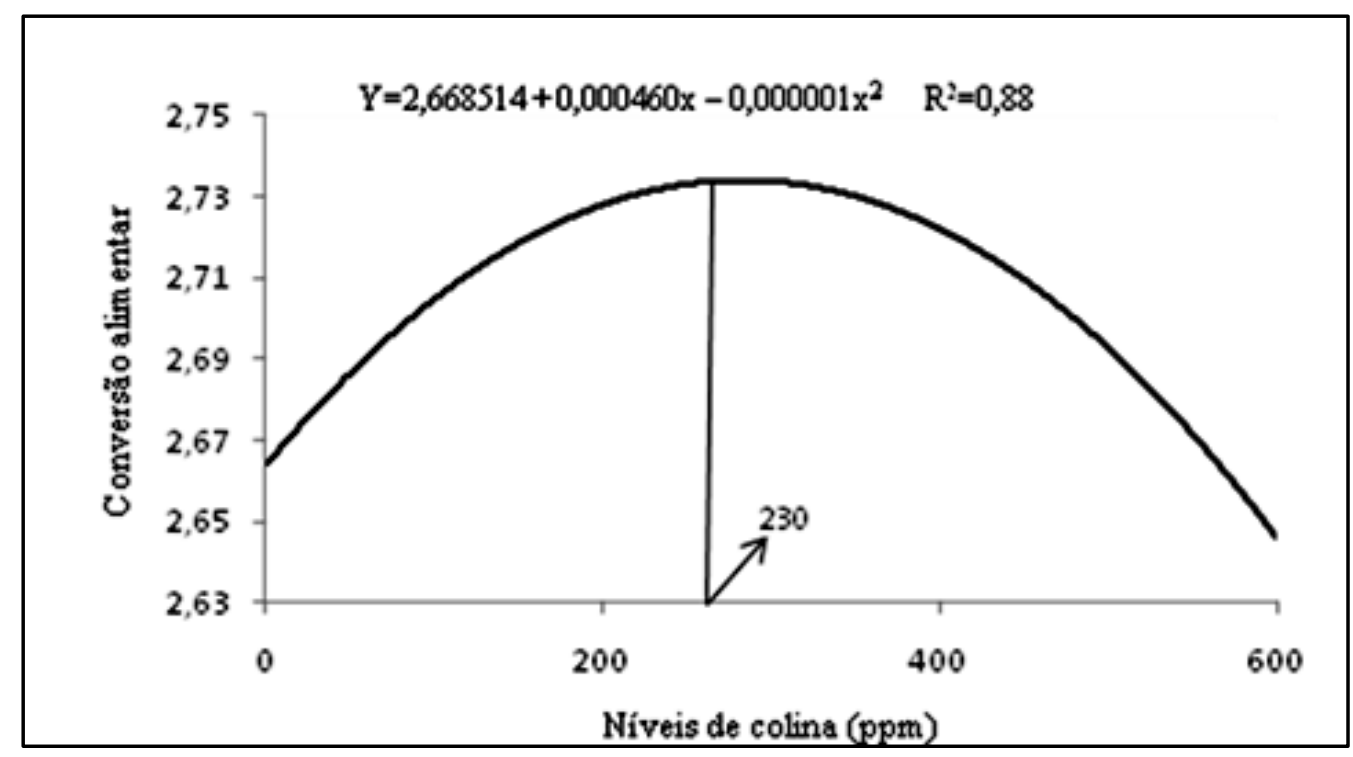

Figura 2 - Efeito dos níveis de colina suplementar sobre a conversão alimentar em codornas japonesas.

Houve interação entre níveis de metionina e colina sobre a massa de ovos, sendo que o nível de $0,75 \%$ de metionina resultou em valores superiores aos obtidos utilizando $0,65 \%$ de metionina nas dietas experimentais, o que já era esperado uma vez que o aumento de metionina na dieta eleva a massa de ovos. Para o nível de $0,65 \%$ de metionina, o nível de 600 ppm de colina proporcionou valores de massa de ovos superiores aos tratamentos com os níveis de $0 \mathrm{e}$ 200 ppm de colina. Já para o nível de $0,75 \%$ de metionina, a inclusão de 600 ppm de colina resultou em valores superiores a quando não houve inclusão de colina na dieta experimental, comprovando que a inclusão de colina possibilita o uso de menor quantidade de metionina na ração para codornas de postura sem redução na massa de ovos.

\section{CONCLUSÃO}

Recomenda-se utilizar 400 ppm de colina em rações de codornas em produção ao utilizar $0,65 \%$ de metionina. Ao utilizar $0,75 \%$ de metionina, a inclusão de $600 \mathrm{ppm}$ de colina tem um efeito aditivo no desempenho produtivo das codornas.

\section{REFERÊNCIAS}

BARROETA, A.; CALSAMIGLIA, S.; CEPERO, R.; LÓPEZ-BOTE, C.; HEMÁNDEZ, J. M. Óptima nutrición vitamínica de los animales para la producción de alimentos de calidad. Barcelona: Pulso ediciones, 2002. 208p.
BELO, M. T. S.; COTTA, J. T. B.; OLIVEIRA, A. I. G. Níveis de metionina em rações de codornas japonesas (Coturnix coturnix japonica), Ciência e Agrotecnologia, Lavras, v.24, n.4, p.1068-1078, 2000.

CORRÊA, G. S. S.; SILVA, M.; CORRÊA, A. B.; ALMEIDA, V.; FONTES, D. O.; TORRES, R. A.; DIONELLO, N. J. L.; FREITAS, L. S.; VENTURA, R. V.; PAUlO, A. A.; SILVA, J. V.; SANTOS, G. G. Exigência de metionina + cistina total para codornas de corte em crescimento. Arquivo Brasileiro de Medicina Veterinária e Zootecnia, Belo Horizonte, v.58, n.3, p.414-420, 2006.

DABBERT, C. B.; LOCHMILLER, R. L.; WALDROUP, P. W.; TEETER, R. G. Examination of the dietary methionine requirements of breeding Northern Bobwhite, Colinus virginarus. Poultry Science, Champaign, v.75, n.8, p.991-997, 1996.

FERREIRA, D. F. SISVAR: pacote computacional. Manual do sistema SISVAR para análises estatísticas. Lavras: Universidade Federal de Lavras, 2000. 66 p.

FREITAS, A. C.; FUENTES, M. F. F.; FREITAS, E. R.; SUCUPIRA, F. S.; OLIVEIRA, B. C. M. Efeito de níveis de proteína bruta e de energia metabolizável na dieta sobre o desempenho de codornas de postura. Revista Brasileira de Zootecnia, v.34, n.3, p. 838-846, 2005.

MURAKAMI, A. E. FURLAN, A. C. ; KIRA, K. C. ; RIBEIRO, R. P. Exigência de metionina para codornas japonesas (Coturnix coturnix japonica) em postura. In: REUNIÃO ANUAL DA SOCIEDADE BRASILEIRA DE ZOOTECNIA, 31, 1994, Maringá, PR. Anais... Maringá: SBZ, 1994. p. 25.

NRC. Committee on animal nutrition. Subcommittee on poultry nutrition. Nutrients Requirements of Poultry. 9. 
ed. Washington: National Academic of Sciences, 1994. $155 \mathrm{p}$.

PINTO, R. et al. Exigência de metionina mais cistina para codornas japonesas em postura. Revista Brasileira de Zootecnia, Viçosa v.32, n.5, p.1166-1173, 2003 a.

PINTO, R. et al. Exigências de metionina mais cistina para codornas japonesas em crescimento. Revista Brasileira de Zootecnia, Viçosa, v.32, n.5, p.1174-1181, 2003b.

ROSTAGNO, H. S. ; ALBINO, L. F. T.; DONZELE, J. L.; GOMES, P. C.; OLIVEIRA, R. F.; LOPES, D. C.; FERREIRA, A. S.; BARRETO, S. L. de T.; EUCLIDES,
R. F. Tabelas Brasileiras para Aves e Suinos Composição de Alimentos e Exigencias Nutricionais. 3. ed. Viçosa: Universidade Federal de Viçosa, 2011. v. 01. $252 \mathrm{p}$.

STRINGHINI, J. H. MOGYCA, N. S. ; CAFÉ, M. B.; S. MORAIS, R. P. de; REZENDE, I. R.; MARTINS, C. L. Níveis de energia metabolizável e metionina para codornas (Coturnix coturnix japonica) em postura. Acta Scientiarum, Maringá, v.20, n.3, p.407-411, 1998.

VIEIRA, I.; CYRINO, J. E. P.; PEZZATO, L. E. Colina e betaína em rações purificadas na nutrição da tilápia do nilo (Oreochromis niloticus). Scientia Agricola, Piracicaba, v.58, n.4, p.675-680, 2001. 